\title{
Pengaruh Sistem Pelayanan, Ketepatan Waktu dan Daya Beli Masyarakat terhadap Loyalitas Menggunakan Jasa Transportasi Bus pada PT. Atlas
}

\section{The effect of service system, timeliness and power of buying community against to loyalty using bus transportation services in PT. Atlas}

\author{
Monalisa Tampubolon*, Miftahul Jannah, Rinaldi Gultom \& Hendra Jonathan \\ Sibarani \\ Jurusan manajemen, Fakultas Ekonomi, Universitas Prima Indonesia, Indonesia
}

Diterima: 26 September 2020; Direview: 11 Oktober 2020; Disetujui: 17 Oktober 2020

*Coresponding Email:monatampu20@gmail.com

\begin{abstract}
Abstrak
Penelitian ini dilakukan untuk mengetahui pengaruh sistem pelayanan, ketepatan waktu dan daya beli masyarakat terhadap loyalitas menggunakan jasa transportasi bus pada PT. Atlas. Metode yang digunakan dalam penelitian ini menggunakan pendekatan kuantitatif dan yakni menggunakan sifat penelitian explanatory. Berdasarkan populasi dalam penelitian ini adalah pelanggan pada pengguna jasa pembelian tiket sebesar 778 orang. Teknik pengambilan sampel dengan menggunakan rumus slovin sebanyak 89 orang yang digunakan dalam penelitian ini. Berdasarkan hasil yang diperoleh dari penelitian ini menggunakan secara parsial diperoleh nilai sistem pelayanan memiliki nilai $t_{\text {hitung }}$

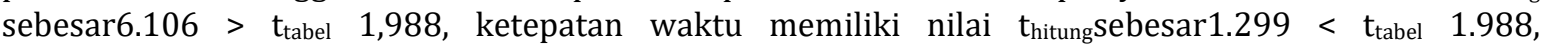
sedangkandaya beli memiliki $t_{\text {hitung }}$ sebesar0.043 $<t_{\text {tabel }} 1,988$ yang berarti ketepatan waktu dan daya beli tidak berpengaruh positif dan signifikan terhadap loyalitas pengguna jasa di PT. ATLAS Medan, sedangkan secara simultan nilai $F_{\text {hitung }}$ sebesar(13.451) $>F_{\text {tabel }}$ sebesar (3.10) dengan nilai sig $0.000<$ 0.05yang berarti sistem pelayanan, ketepatan waktu dan daya beli masyarakat berpengaruh positif dan signifikan terhadap loyalitas pengguna jasa transportasi.
\end{abstract}

Kata Kunci: Service System, Timeliness, Public Purchasing Power, Loyalty

\begin{abstract}
This study was conducted to determine the effect of service system, timeliness and power of buying community against to loyalty using bus transportation services in PT. Atlas. The method used in this study uses a quantitative approach and uses explanatory research characteristics. Based on the population in this study, the customer for the ticket purchasing service was 778 people. The sampling technique used the Slovin formula as many as 89 people used in this study. Based on the results obtained from this study using partially obtained the value of the service system has a tcount of 6,106>1,988, punctuality has a tcount of 1,299 <ttable 1,988, while purchasing power has a tcount of $0.043<$ ttable 1.988 which means punctuality and purchasing power has no positive and significant effect on service user loyalty at PT. ATLAS Medan, while simultaneously the value of Fcount is (13.451)> Ftable of (3.10) with a sig value of $0.000<0.05$, which means that the service system, timeliness and purchasing power of the community have a positive and significant effect on the loyalty of transportation service users.
\end{abstract}

Keywords: Service System, Timeliness, Public Purchasing Power, Loyalty

How to Cite: Tampubolon, M., Jannah, M., Gultom, R., \& Sibarani, H.J. (2020). Pengaruh Sistem Pelayanan, Ketepatan Waktu Dan Daya Beli Masyarakat Terhadap Loyalitas Menggunakan Jasa Transportasi Bus Pada Pt.Atlas. Journal of Education, Humaniora and Social Sciences (JEHSS). 3 (2): 566 576. 


\section{PENDAHULUAN}

Pada era kemajuan teknologi ini akses transportasi memiliki peranan penting dalam penilaian penggunaan jasa transportasi, untuk itu sistem pelayanan pembelian tiket menjadi salah satu penilaian pengguna jasa untuk menggunakan jasa transportasi angkutan bus umum, sistem pelayanan dan pembelian tiket yang baik dapat membantu tercapainya penjualan produk dan jasa yang ditawarkan sesuai dengan keinginan penumpang, hal ini akan tercapai tergantung bagaimana kualitas sistem pelayanan jasa yang diberikan perusahaan transportasi. Disamping itu penjualan tiket dapat meningkatkan laba dalam mengembangkan operasional perusahaan. Oleh karena itu, untuk meningkatkan penjualan perusahaan harus meningkatkan sistem pelayanan agar pengguna jasa mudah dalam mengambil keputusan dalam pembelian produk dan jasa perusahaan.

PT. Atlas merupakan salah satu perusahaan yang bergerak di bidang jasa transportasi bus angkutan umum dan berdiri sejak tahun 1970 di kota Medan yang beralamat di Jl.Gagak Hitam No.78 Medan Sunggal, Sumatera Utara.Perusahaan ini memiliki beberapa cabang di kota Medan untuk memudahkan para penumpang untuk membeli tiket bus. PT.Atlas menyediakan beberapa tipe armada bus, yaitu tipe standart, executive, dan executive VIP. Dari hasil wawancara antara pihak peneliti dan pihak perusahaan untuk permasalahan loyalitas konsumen diperoleh penurunan pada kepuasan konsumen terhadap kualitas jasa yang diberikan pihak perusahaan. Dari data keluhan yang diperoleh perusahaan setiap bulannya terjadi peningkatan di bulan Juli sebanyak 5 orang, seperti misalnya kurangnya keamanan bagi konsumen yang berada di luar area tunggu dan kurang besarnya ruang tunggu penumpang saat menunggu jam keberangkatan bus untuk berangkat yang akan menimbulkan kurangnya ketidak-nyamanan penumpang pada saat menunggu serta minimnya keramah-tamahan komunikasi antara karyawan pada konsumen.

Dalam sistem pembelian tiket ada beberapa yang mempengaruhi keputusan pembelian tiket, banyak perusahaan yang sudah melakukan pelayanan penjualan tiket secara online yang dapat memudahkan konsumen dalam pemesanan tanpa harus membeli secara langsung ke loket penjualan tiket. Saat ini PT.Atlas masih menjual tiket menggunakan sistem pelayanan manual yaitu datang langsung ke loket atau melakukan pemesanan dengan menghubungi pihak perusahaan melalui via telepon. Dalam meningkatkan penjualan perusahaan harus memperhatikan keputusan pembelian karena dengan adanya keputusan pembelian adanya penjualan, hal ini akan terjadi penurunan penjualan tiket yang dapat mempengaruhi loyalitas pengguna jasa. Seperti yang dikatakan (Amelia, 2017; Lubis, 2014; Sihaloho, 2016; Mulia, 2016).

Ketepatan waktu atau timeline yaitu aspek pendukung relepansi, dan yang tersedianya informasi dalam pengambilan keputusan sebelum informasi tersebut kehilangan kapasitas pengaruhnya dalam mempengaruhi keputusan. Ketepatan waktu atau keterlambatan dapat terlihat dari lamanya jadwal keberangkatan yang telah ditetapkan perusahaan dan banyaknya pengguna jasa yang memiliki waktu yang terbatas untuk menunggu jam keberangkatan. Terlihat dari keluhan pengguna jasa di setiap bulannya terjadi peningkatan di bulan Juni sebanyak 10 orang yang mengeluh dikarenakan telatnya jam keberangkatan. Hal ini didukung oleh penelitian yang dilakukan Dede Apriyadi dengan judul "analisis pengaruh ketepatan waktu, fasilitas, dan tiket terhadap kepuasan penumpang kereta api di stadium purwosari" bahwa ketepatan waktu berpengaruh positif dan signifikan terhadap kepuasan penumpang kereta api bengawan di stasiun purwosari, yang artinya ketepatan waktu sangat penting untuk diperhatikan agar dapat meningkatkan kepercayaan pelanggan sehingga mereka akan selalu setia atau loyal dalam menggunakan jasa transportasi perusahaan.

Selain ketepatan waktu, daya beli masyarakat juga menjadi faktor penting dalam penjualan tiket transportasi. Salah satu faktor yang berpengaruh pada daya beli pengguna jasa biasanya seperti tingkat pendapatan sehingga mereka akan, kebiasaan pengguna jasa dan juga kebutuhan akan suatu perjalanan. Seperti yang dikatakan Telah terjadi penurunan penjualan tiket selama satu tahun yang terjadi di bulan Februari yang tidak tercapainya target sebanyak Rp.54.349.000penjualan tiket tahun 2018. Persentase tertinggi pencapaian target penjualan tiket pada bulan Juni sebanyak Rp.200.170.000,- terjadi dikarenakan pada hari besar keagamaan. Pendapatan 
pengguna jasa juga menjadi faktor penting dalam daya beli, Dengan penelitian terdahulu Herosian, Mila dengan judul "Pengaruh Penggunaan Digital Marketing Dan Kemudahan Akses Layanan Aplikasi Belanja Online Dalam Peningkatan Daya Beli Masyarakat Kota Medan Di Era Revolusi Industri Marketing 4.0" Bahwa daya beli masyarakat berpengaruh positif dan signifikan hal ini dikarenakan keinginan pengguna jasa untuk membeli tiket untuk orang-orang yang mudik atau pulang ke kampung halaman pada hari hari besar keagamaan.

\section{METODE PENELITIAN}

Penelitian ini dilakukan di PT. ATLAS dengan menggunakan data primer dan sekunder. Adapun sifat penelitian adalah deskritif explanatorydengan tujuan untuk menelaah kausalitas antar variabel yang menjelaskan suatu fenomena tertentu.

Menurut Sugiyono (2017 Bahwa populasi merupakan salah satu wilayah generalisasi yang terdiri dari: objek/ subjek yang memiliki karakteristik dan kuantitas tertentu yang ditetapkan oleh peneliti untuk mempelajarinya dan kemudian ditarik kesimpulannya.

Tabel 1

Data Pelanggan Pengguna Jasa Pembelian Tiket di PT ATLAS MedanTakengon dari Bulan Januari-Desember 2018

\begin{tabular}{lll}
\hline No & Bulan & Jumlah Pembelian Tiket Pelanggan \\
\hline 1 & Januari & 560 \\
\hline 2 & Februari & 386 \\
\hline 3 & Maret & 455 \\
\hline 4 & April & 356 \\
\hline 5 & Mei & 567 \\
\hline 6 & Juni & 1442 \\
\hline 8 & Juli & 1076 \\
\hline 9 & Sepustus & 943 \\
\hline 10 & Oktober & 694 \\
\hline 11 & November & 720 \\
\hline 12 & Desember & 799 \\
\hline Total & & 1335 \\
\hline Rata-rata & 9333 \\
\hline
\end{tabular}

Sumber : PT ATLAS, 2018

Menurut Sugiyono (2017), menyatakan bahwa sampel ialah bagian dari jumlah dan karakteristik yang dimiliki oleh populasi tersebut, untuk itu sampel yang di ambil dari populasi harus betul-betul representatif (mewakili). Kesimpulannya akan dapat diberlakukan untuk populasi. Pendekatan sampel menggunakan Non Probability Sampling. Jenis Sampling yang digunakan adalah Accidental Sampling artinya teknik untuk menentukan sampel dari populasi yang mempunyai ciri-ciri tertentu sampai jumlah (kuota) yang diinginkan. Menurut Sanusi (2011) dalam menentukan jumlah, sampel yang akan digunakan peneliti memutuskan untuk menggunakan rumus slovin dikarenakan jumlah populasi dalam penelitian ini yang besar dan keterbatasan waktu penelitian, rumus slovin yang digunakan dalam penelitian ini adalah sebagai berikut:

$\mathrm{N}$

$$
\begin{aligned}
& n=\frac{}{1+\mathrm{N} \mathrm{e}^{2}} \\
& \mathrm{~N}=\text { populasi } \\
& \mathrm{e}=\text { persentase error }(10 \%)
\end{aligned}
$$


Dengan rumus di atas, maka sampel (n) penelitian ini adalah:

778

$$
\begin{aligned}
\mathbf{n} & =\overline{1+778 \times(0.1)^{2}} \\
& =88,610 \sim 89 \text { orang }
\end{aligned}
$$

Berdasarkan hasil perhitungan di atas, maka jumlah sampel yang akan digunakan dalam penelitian ini adalah 89 orang, dan 30 orang digunakan dari sisa populasi yang tidak digunakan dalam sampel penelitian untuk uji validitas dan reliabilitas sehingga jumlah responden dalam penelitian ini sebanyak 119. Teknik pengumpulan data dalam penelitian ini menggunakan: wawancara dilakukan kepada HRD PT. Atlas Medan, studi dokumentasi, diperoleh dari bukubuku, jurnal dan situs internet dan kuesioner, diberikan kepada pengguna jasa PT.ATLAS.

Tabel 2.

\begin{tabular}{|c|c|c|c|}
\hline Variabel & Definisi & Indikator & Skala \\
\hline $\begin{array}{l}\text { Sistem } \\
\text { Pelayanan } \\
\left(\mathrm{X}_{1}\right)\end{array}$ & $\begin{array}{l}\text { Pelayanan merupakan salah satu kegiatan } \\
\text { yang dilaksanakan oleh seseorang atau } \\
\text { sekelompok orang dengan landasan } \\
\text { faktor materi yang melalui sistem } \\
\text { prosedur dan metode tertentu dalam } \\
\text { bentuk usaha yang memenuhi } \\
\text { kepentinggan orang lain sesuai dengan } \\
\text { haknya. Sumber: Moenir (2010) }\end{array}$ & $\begin{array}{l}\text { Efesiensi (efficiency) } \\
\text { Pemenuhan (fulfillment) } \\
\text { Ketersediaan sistem (system } \\
\text { availability) } \\
\text { Rahasia privasi } \\
\text { Sumber: Jain dan Kumar (2011) }\end{array}$ & Likert \\
\hline $\begin{array}{l}\text { Ketepatan } \\
\text { Waktu } \\
\left(\mathrm{X}_{2}\right)\end{array}$ & $\begin{array}{l}\text { Ketepatan waktu atau timelines } \\
\text { merupakan salah satu faktor penting } \\
\text { dalam menyajikan suatu informasi yang } \\
\text { relevan. Sumber: Wahab, Arfan, dan } \\
\text { Bakar (2012) }\end{array}$ & $\begin{array}{l}\text { Ketepatan waktu kedatangan bus } \\
\text { Ketepatan waktu keberangkatan } \\
\text { Ketepatan waktu berhenti di } \\
\text { terminal tujuan. } \\
\text { Sumber: Apriyadi (2017) }\end{array}$ & Likert \\
\hline $\begin{array}{l}\text { Daya Beli } \\
\left(\mathrm{X}_{3}\right)\end{array}$ & $\begin{array}{l}\text { Daya beli adalah kemampuan masyarakat } \\
\text { sebagai konsumen untuk membeli barang } \\
\text { atau jasa yang di butuhkan. Sumber: } \\
\text { Supawi (2016) }\end{array}$ & $\begin{array}{l}\text { Tingkat Pendapatan } \\
\text { Tingkat Pendidikan } \\
\text { Tingkat Kebutuhan } \\
\text { Kebiasaan Masyarakat } \\
\text { Sumber: Sibarani, Hendra Jonathan } \\
(2019)\end{array}$ & Likert \\
\hline $\begin{array}{l}\text { Loyalitas } \\
\text { (Y) }\end{array}$ & $\begin{array}{l}\text { Loyalitas merupakan } \\
\text { pelanggan yang bertahan } \\
\text { mendalam untuk berlangganan kembali } \\
\text { atau melakukan pembelian ulang } \\
\text { produk/jasa terpilih secara konsisten } \\
\text { pada masa yang akan datang, meskipun } \\
\text { pengaruh situasi dan usaha-usaha } \\
\text { pemasaran mempunyai potensiuntuk } \\
\text { menyebabkan perubahan prilaku. } \\
\text { Sumber: Oliver (2010) }\end{array}$ & $\begin{array}{l}\text { Pembelian ulang } \\
\text { Berkomentar positif } \\
\text { Merekomendasikan dan mengajak } \\
\text { orang lain } \\
\text { Pelanggan sering berkunjung } \\
\text { Sumber: Tjiptono (2014) }\end{array}$ & Likert \\
\hline
\end{tabular}

Defenisi Operasional Variabel

\section{HASIL DAN PEMBAHASAN}

\section{Analisis Statistik Diskriptif}

Uji descriptive merupakan teknik yang dilakukan dengan cara menggambarkan ciri-ciri seperti menunjukkan jumlah pengukuran $(\mathrm{N})$, nilai minimum, nilai maksimum, nilai rata-rata (Mean), standart deviasi (Std). Hasil pengujian yang telah dilakukan dapat dilihat pada tabel di bawah ini: 
Tabel 3

Statistik Deskriptif

\begin{tabular}{|c|c|c|c|c|}
\hline & Sistem Pelayanan & Ketepatan Wakti & Daya Beli Masyarakat & Loyalitas \\
\hline Valid & 89 & 89 & 89 & 89 \\
\hline Mean & 30.1910 & 22.3146 & 31.9438 & 29.3146 \\
\hline Std. Deviation & 1.54388 & 2.77405 & 4.42708 & 2.52531 \\
\hline Minimum & 25.00 & 19.00 & 24.00 & 23.00 \\
\hline Maximum & 34.00 & 28.00 & 37.00 & 34.00 \\
\hline
\end{tabular}

Sumber: Data primer (2020)

Pada tabel 3. dapat dilihat bahwa deskriptif statistik menjelaskan bahwa masing-masing variabel nilai-nilai yang berbeda. seperti variabel sistem pelayanan memiliki rata-rata sebesar 30.1910 dengan std.deviationnya 1.54388 dan juga nilai tertinggi sebesar 34.00 serta nilai terendah sebesar 25.00. Dan pada variabel ketepatan waktu memiliki rata-rata sebesar 22.3146 dengan std.deviationnya 2.77405 dan juga nilai tertinggi sebesar 28.00 serta nilai terendah sebesar 19.00. Pada variabel daya beli memiliki rata-rata sebesar 31.9438 dengan std.deviationnya 4.42708 dan juga nilai tertinggi sebesar 37.00 serta nilai terendah sebesar 24.00.

Pada variabel loyalitas masyarakat memiliki rata-rata sebesar 29.3146 dengan std.deviationnya 2.52531 dan juga nilai tertinggi sebesar 34.00 serta nilai terendah sebesar 23.00.

\section{Uji Asumsi Klasik \\ Uji Normalitas}

Uji normalitas menunjukkan bahwa variabel dependen dan variabel independen dalam model regresi mempunyai distribusi normal atau tidak. Uji normalitas dapat dilakukan melalui dua pendekatan yaitu melalui grafik (histogram dan P-P Plot):

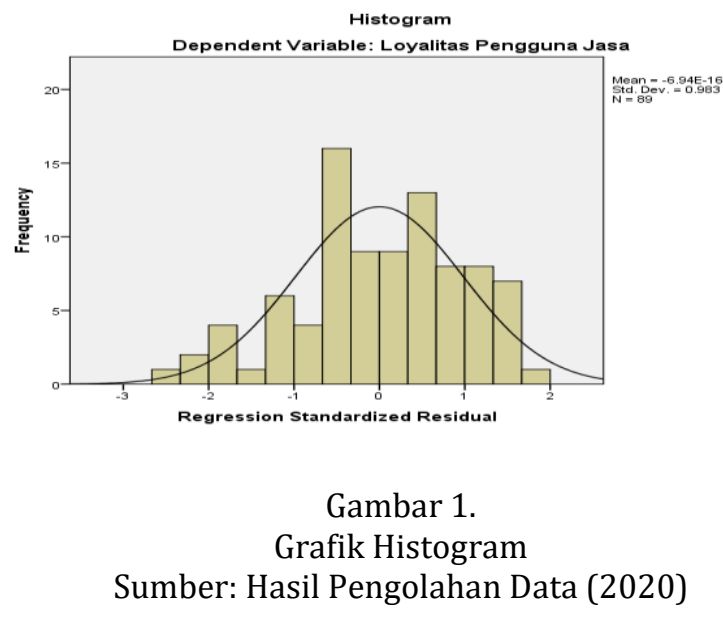

Grafik histogram pada gambar 1 menunjukkan pola distribusi normal karena grafik kecembungan seimbang ditengah maka data dinyatakan berdistribusi secara normal. Demikian pula hasil uji normalitas dengan menggunakan grafik p-plot pada gambar 2. 


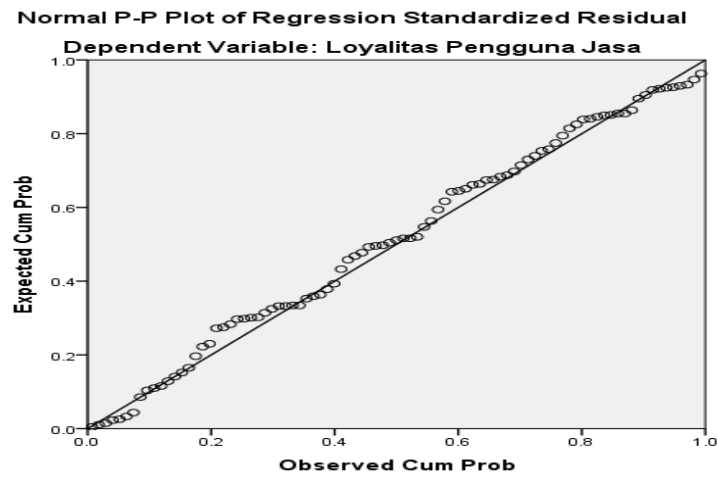

Gambar 2.

Grafik P - P Plot

Sumber: Hasil Pengolahan Data (2020)

Hasil grafik 2 P-P Plot, terlihat bahwa titik-titik PP-Plot bearada diantara garis diagonal dan penyebarannya mengikuti arah garis diagonal. Maka hal ini menunjukkan bahwa data dinyatakan berdistribusi normal atau lulus uji normalitas data. Dan uji normalitas dalam penelitian ini menggunakan metode One-Sample Kolmogorov-Smirnov Test. Adapun hasil dari uji tersebut adalah sebagai berikut:

Tabel 4

Uji Kolmogorov Smirnov One-Sample Kolmogorov-Smirnov Test

\begin{tabular}{lll}
\hline & & Unstandardized Residual \\
\hline $\mathrm{N}$ & & 89 \\
Normal Parametersa,, $\mathrm{b}$ & Mean &, 0000000 \\
& Std. Deviation & 2,07949289 \\
Most Extreme Differences & Absolute &, 066 \\
& Positive &, 041 \\
& Negative &,- 066 \\
Kolmogorov-Smirnov Z & &, 627 \\
Asymp. Sig. (2-tailed) & &, 827 \\
\hline
\end{tabular}

a. Test distribution is Normal.

b. Calculated from data.

Sumber: Hasil Pengolahan Data (2020)

Uji One-Sample Kolmogorov-Smirnov Test memiliki ketentuan seperti, jika nilai signifikan yang dihasilkan $>0,05$ maka distribusi data normal. Sebaliknya, jika nilai signifikansi yang dihasilkan < 0,05 maka data distribusi tidak normal. Berdasarkan hasil uji normalitas diketahui nilai signifikansi $0,827>0,05$ maka dapat disimpulkan bahwa data yang digunakan dalam penelitian ini nilai residual berdistribusi normal.

\section{Uji Multikoloneritas}

Yang dimaksud dengan uji multikoloneritas suatu keadaan dimana satu atau lebih variabel independen dinyatakan kombinasi linier variabel independen lainnya. Uji multikolineritas dengan Collinary Diagnostic mengidentifikasikan jika nilai tolerance variabel independen $>0,10$ dan nilai VIF $<10$ menunjukkan bahwa tidak adanya multikolenieritas antara variabel independen dalam model regresi. Adapun hasil uji tersebut sebagai berikut: 


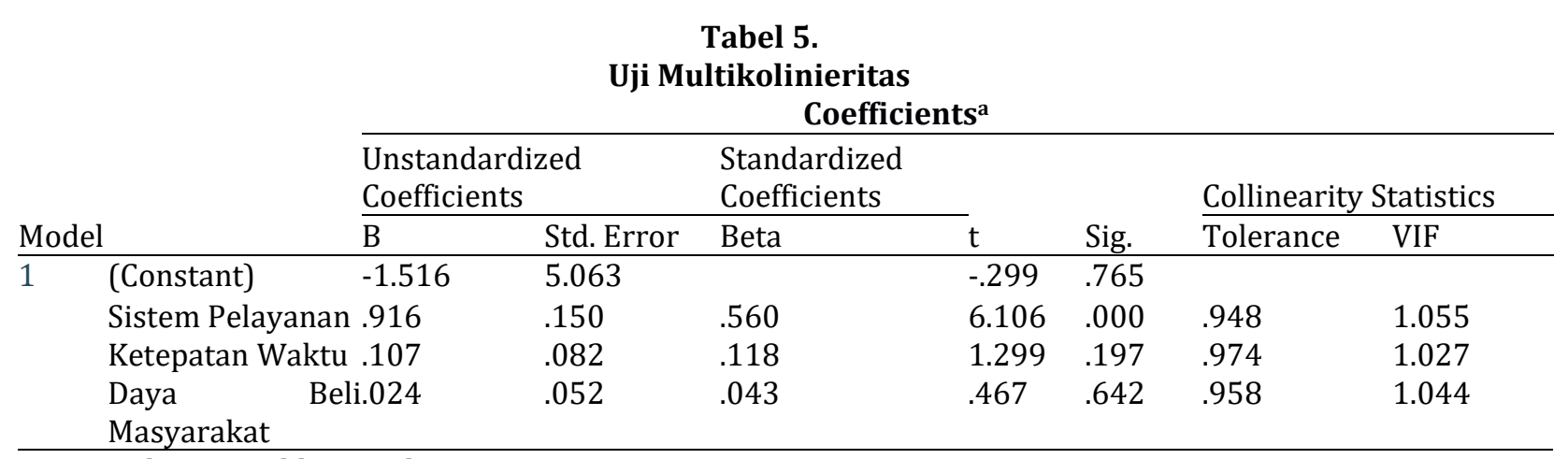

a. Dependent Variable: Loyalitas Pengguna Jasa

Sumber: Hasil Pengolahan Data (2020)

Berdasarkan tabel 5 dapat dilihat bahwa nilai tolerance untuk variabel Sistem Pelayanan sebesar $(0,948)>0,10$ dan nilai VIF $(1,055)<10$ menunjukkan tidak adanya multikolinieritas. Nilai tolerance untuk Ketepatan Waktu sebesar $(0,974)>0,10$ dan nilai VIF $(1,027)<10$ menunjukkan tidak adanya multikolinieritas. Nilai tolerance Daya Beli sebesar $(0,958)>0,10$ dan VIF $(1,044)<10$ menunjukkan tidak adanya multikolinieritas. Dapat disimpulkan bahwa data dinyatakan terbebas dari masalah Multikolinieritas atau lulus uji Multikolinieritas.

\section{Uji Heteroskedastisitas}

Untuk mengetahui ada tidaknya heteroskedastisitas adalah dengan melihat hasil signifikansi dari gambar scatterplot dan uji glejser di bawah ini:

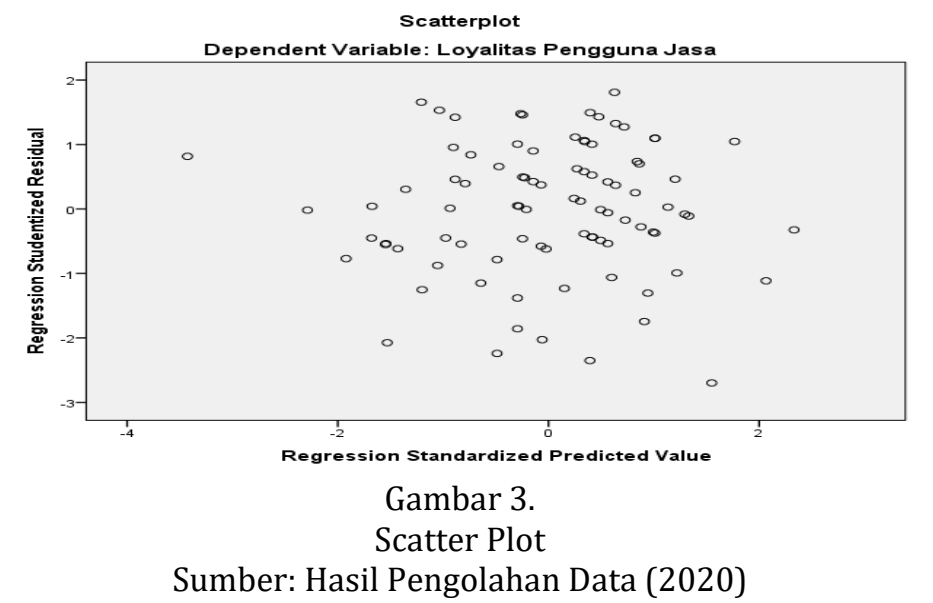

Dari hasil gambar scatterplot menunjukkan bahwa titik-titik yang dihasilkan menyebar secara acak dan tidak membentuk suatu pola atau trend garis tertentu. Gambar scatterplot diatas menunjukkan bahwa sebaran data ada di sekitar titik nol. Hasil pengujian ini menunjukkan bahwa model regresi ini bebas dari masalah heteroskedastisitas, dengan perkataan lain: variabel-variabel yang akan diuji dalam penelitian ini bersifat homokedastis dan dilihat dari hasil uji glejser table 6: 
Tabel 6

Hasil Uji Glejser

Coefficients $^{\text {a }}$

\begin{tabular}{lllllll}
\hline & & \multicolumn{2}{l}{ Unstandardized Coefficients } & \multicolumn{2}{l}{ Standardized Coefficients } & \\
\cline { 3 - 6 } Model & & $\mathrm{B}$ & Std. Error & Beta & $\mathrm{t}$ & Sig. \\
\hline 1 & (Constant) & 1.464 & 2.996 & & .488 & .626 \\
& Sistem Pelayanan & .054 & .089 & .067 & .604 & .547 \\
& Ketepatan Waktu & -.015 & .049 & -.034 & -.312 & .756 \\
& Daya Beli & -.034 & .031 & -.121 & -1.103 & .273 \\
\hline
\end{tabular}

a. Dependent Variable: RES2

Sumber: Hasil Pengolahan Data (2020)

Berdasarkan uji glejser table 6 diketahui nilai signifikansi variabel sistem pelayanan sebesar 0,547 >0,05 dengan demikian tidak terjadi heteroskedastisitas. Sementara, nilai signifikansi variabel ketepatan waktu sebesar $0,756>0,05$ yang artinya tidak terjadi heteroskedastisitas. Dan nilai signifikansi variabel daya beli sebesar 0,273 >0,05 artinya tidak terjadi heteroskedastisitas. Karena nilai signifikan ketiga variabel di atas lebih besar dari 0,05 maka dapat disimpulkan bahawa ketiga variabel tidak terjadi heteroskedastisitas.

\section{Hasil Analisis Data Penelitian}

\section{Model Penelitian Linier Berganda}

Uji regresi linier berganda digunakan untuk mengetahui pengaruh variabel bebas secara bersama-sama terhadap variabel terikat. Regresi linier berganda dilakukan dengan menggunakan suatu program pengolah data. Rumusan analisis regresi linier berganda dilihat sebagai berikut:

Tabel 7.

Analisis Regresi Linier Berganda

Coefficients $^{\mathbf{a}}$

\begin{tabular}{|c|c|c|c|c|c|c|c|c|}
\hline \multirow{2}{*}{\multicolumn{2}{|c|}{ Model }} & \multicolumn{2}{|c|}{$\begin{array}{l}\text { Unstandardized } \\
\text { Coefficients }\end{array}$} & \multirow{2}{*}{$\begin{array}{l}\text { Standardized } \\
\text { Coefficients } \\
\text { Beta }\end{array}$} & \multirow[t]{2}{*}{$-t$} & \multirow[t]{2}{*}{ Sig. } & \multicolumn{2}{|c|}{ Collinearity Statistics } \\
\hline & & $\bar{B}$ & Std. Error & & & & Tolerance & VIF \\
\hline \multirow[t]{4}{*}{1} & (Constant) & -1.516 & 5.063 & & -.299 & .765 & & \\
\hline & Sistem Pelayanan & .916 & .150 & .560 & 6.106 & .000 & .948 & 1.055 \\
\hline & Ketepatan Waktu & .107 & .082 & .118 & 1.299 & 197 & .974 & 1.027 \\
\hline & Daya Beli Masyarakat & .024 & .052 & .043 & .467 & .642 & .958 & 1.044 \\
\hline
\end{tabular}

a. Dependent Variable: Loyalitas Pengguna Jasa

Dependent Variable: Loyalitas Masyarakat

Sumber: Hasil Pengolahan Data (2020)

Hasil output SPSS tabel Coefficients maka persamaan regresinya adalah:

Interpretasi

$$
Y=-1,516+0,916 X_{1}+0,107 X_{2}+0,024 X_{3}+e
$$

Jika segala seuatu pada variabel-variabel independent dianggap konstan maka nilai sistem pelayanan, ketepatan waktu dan daya beli tidak berubah maka nilai loyalitas masyarakat sebesar $-1,516$ satuan.

Jika Sistem pelayanan meningkat satu satuan maka Loyalitas masyarakat akan meningkat sebesar 0,916 satuan

Jika Ketepatan waktu meningkakan satu satuan Loyalitas masyarakat akan meningkat sebesar 0,107 satuan

Jika daya beli meningkat satu satuan loyalitas masyarakat akan meningkat sebesar 0,024 satuan 


\section{Koefisien Determinasi}

Pada koefisien determinasi (Adjusted R2) merupakan untuk mengukur seberapa jauh kemampuan model dalam menerangkan variasi variabel dependen. Nilai yang mendekati berarti variabel-variabel bebas memberikan hampir semua informasi yang dibutuhkan untuk memprediksi variabel terikat.

Tabel 8

Uji Koefisien Determinasi (R2)

Model Summaryb

Model R R Rquare Adjusted R Square Std. Error of the Estimate

\begin{tabular}{lllll}
\hline 1 & $.567 \mathrm{a}$ & .322 & .298 & 2.11587
\end{tabular}

a. Predictors: (Constant), Daya Beli Masyarakat, Ketepatan Waktu, Sistem Pelayanan

b. Dependent Variable: Loyalitas Pengguna Jasa

Sumber: Hasil Pengolahan Data (2020)

Dari table 8 dapat diketahui bahwa nilai $\mathrm{R}$ sebesar 0,567 sebagai nilai kolerasi berganda artinya sistem pelayanan, ketepatan waktu dan daya beli memiliki keeratan hubungan yang sedang dengan loyalitas masyarakat. Nilai R Square dan Adjusted R Square mewakili nilai koefisien determinasi, namun regresi linier berganda lebih tepat menggunakan Nilai Adjusted $\mathrm{R}$ Square sebesar 0.298 atau 29,8 \%, Artinya Sistem pelayanan, Ketepatan waktu dan Daya mampu mempengaruhi Loyalitas masyarakat sebesar 29,8\% sisanya sebesar 70,2\% Loyalitas masyarakat dipengaruhi oleh variabel lain yang tidak diteliti dalam penelitian ini seperti tarif dan lokasi.

\section{Uji Secara Simultan (Uji-F)}

Uji-F (Fisher) pada dasarnya menunjukkan apakah semua variabel bebas yang dimaksudkan dalam penelitian mempunyai pengaruh secara bersama-sama terhadap variabel terikat, seperti tabel 9.

Tabel 9. Uji Simultan (Uji - F)

ANOVAa

\begin{tabular}{lllllll}
\hline Model & & Sum of Squares & Df & Mean Square & F & Sig. \\
\hline 1 & Regression & 180.653 & 3 & 60.218 & 13.451 & $.000 \mathrm{~b}$ \\
& Residual & 380.538 & 85 & 4.477 & & \\
& Total & 561.191 & 88 & & & \\
\hline
\end{tabular}

a. Dependent Variable: Loyalitas Pengguna Jasa

b. Predictors: (Constant), Daya Beli Masyarakat, Ketepatan Waktu, Sistem Pelayanan

Sumber: Hasil Pengolahan Data (2020)

Hasil uji ANOVA dengan analisis F (Fisher) diketahui nilai Fhitung sebesar (13.451) > Ftabel sebesar (3.10) dengan nilai sig $0.000<0.05$ maka Ha diterima. Artinya Sistem pelayanan, Ketepatan waktu dan Daya berpengaruh signifikan terhadap Loyalitas masyarakat.

Uji Secara Parsial (Uji-t)

Hasil uji-t dapat dilihat pada tabel berikut:

Tabel 10. Uji Parsial (Uji - t)

Coefficients $^{\mathrm{a}}$

\begin{tabular}{|c|c|c|c|c|c|c|}
\hline \multirow{2}{*}{\multicolumn{2}{|c|}{ Model }} & \multicolumn{5}{|c|}{ Unstandardized Coefficients Standardized Coefficients } \\
\hline & & $\mathrm{B}$ & Std. Error & Beta & $\mathrm{T}$ & Sig. \\
\hline \multirow[t]{4}{*}{1} & (Constant) & -1.516 & 5.063 & & -.299 & .765 \\
\hline & Sistem Pelayanan & .916 & .150 & .560 & 6.106 & .000 \\
\hline & Ketepatan Waktu & .107 & .082 & .118 & 1.299 & .197 \\
\hline & Daya Beli Masyarakat & .024 & .052 & .043 & .467 & .642 \\
\hline
\end{tabular}

a. Dependent Variable: Loyalitas Pengguna Jasa

Dependent Variable: Loyalitas Masyarakat

Sumber : Hasil Pengolahan Data (2020) 
Hasil uji-t secara parsial diketahui bahwa:

Nilai thitung sistem pelayanan sebesar $6.106>$ ttabel 1,988 kemudian nilai sig $0.000<0.05$ sehingga Ha diterima, artinya Sistem pelayanan berpengaruh signifikan terhadap Loyalitas masyarakat di PT. ATLAS Medan.

Nilai thitung ketepatan waktu sebesar $1.299<$ ttabel 1.988 kemudian nilai sig $0.197>0.05$ sehingga Ha ditolak, artinya ketepatan waktu tidak berpengaruh signifikan terhadap Loyalitas masyarakat di PT. ATLAS Medan.

Nilai thitung Daya beli sebesar $0.043<$ ttabel 1,988 kemudian nilai sig $0.642>0.05$ maka Ha ditolak, artinya daya beli tidak berpengaruh signifikan terhadap loyalitas masyarakat di PT. ATLAS Medan.

\section{SIMPULAN}

Hasil hipotesis ini yang diajukan dalam penelitian adalah sistem pelayanan berpengaruh terhadap loyalitas masyarakat. Hasil uji t (nilai t regresi) menunjukkan bahwa variabel sistem pelayanan memiliki koefisien regresi sebesar 6,106 maka (thitung 6,106 > ttabel 1,988) kemudian nilai sig $0.000<0.05$ artinya Ha diterima dan berpengaruh signifikan terhadap Loyalitas masyarakat di PT. ATLAS Medan. Berdasarkan penelitian ini berpengaruh signifikan terhadap loyalitas masyarakat, jika semakin baik pelayanan yang dilakukan oleh seseorang maka semakin baik pula sistem berkerjanya untuk memenuhi kepentingan di PT.ATLAS Medan. Hasil hipotesis ini yang diajukan dalam penelitian adalah ketepatan waktu tidak berpengaruh terhadap loyalitas masyarakat. Hasil uji t (nilai t regresi) menunjukkan bahwa variabel ketepatan waktu memiliki koefisien regresi sebesar 1,299 maka (thitung 1,299 > ttabel 1,988) kemudian nilai sig $0.197>0.05$ artinya Ha ditolak dan tidak berpengaruh signifikan terhadap Loyalitas masyarakat di PT. ATLAS Medan. Berdasarkan penelitian ini tidak berpengaruh signifikn terhadap loyalitas masyarakat karena ketepatan waktu merupakan salah satu karakteristik kualitatif yang harus dipenuhi agar laporan yang disajikan relevan untuk membantu dalam pembuat keputusan. Hasil hipotesis ini yang diajukan dalam penelitian adalah daya beli tidak berpengaruh terhadap loyalitas masyarakat. Hasil uji t (nilai t regresi) menunjukkan bahwa variabel daya beli memiliki koefisien regresi sebesar 1,335 maka (thitung 1,335 < ttabel 1,988) kemudian nilai sig $0.642>0.05$ artinya Ha ditolak dan tidak berpengaruh signifikan terhadap Loyalitas masyarakat di PT. ATLAS Medan. Berdasarkan penelitian diatas dapat disimpulkan bahwa daya beli tidak selalu berpengaruh seacara signifikan terhadap loyalitas masayarakat. Ada baiknya juga bahwa PT. ATLAS Medan tidak hanya fokus pada sistem pelayanan dan ketepatan waktu saja, melainkan fokus juga pada faktor-faktor lainya yang lebih berpengaruh terhadap loyalitas masyarakat maupun pada PT. ATLAS Medan.

\section{DAFTAR PUSTAKA}

Adisasmita, R. \& Adji, A.S. (2006). Manajemen Transportasi Darat. Yogyakarta: Graha Ilmu. Apriyadi, D (2017). Analisis Pengaruh Ketepatan Waktu, Fasilitas Dan Harga Tiket Terhadap Kepuasan Penumpang Kereta Api Di Stasiun Purwosari, Magistra no.99 Th.XXX maret 2017.

Ghozali, I (2016). Aplikasi analisis multivariate dengan program SPSS.Universitas Diponogoro.

Herosian, M (2019). Pengaruh Penggunaan Digital Marketing Dan Kemudahan Akses Layanan Aplikasi Belanja Online Dalam Peningkatan Daya Beli Masyarakat Kota Medan Di Era Revolusi Industri Marketing 4.0. JURNAL AKBAR JUARA.Volume 4 nomor 5 edisi Desember 2019 (45-62).

Jain, P, \& Kumar, N, (2011). Measurement of e-service quality: an empirical study on only railway ticket reservation website service. Sri Krishna international research \& educational consurtium. Vol. 2, No. 1, 2011 pp, 22-38.

Miranti, (2016), Jumlah Nilai Ekspor, Impor Dan Pertumbuhan Ekonomi Terhadap Nilai Tukar Dan Daya Beli Masyarakat Di Indonesia. Study pada Bank Indonesia periode tahun 2006: IV-2015: III. JURNAL ADMINISTRASI BISNIS (JAB), Vol. 34 No. 1, Hal 115.

Oliver, R.L, (2010). Satisfaction: A Behavional perpective on the customer. New York.

Pawenang, S., (2016). Modul Perkuliahan Lingkungan Ekonomi Bisnis. Surakarta: Program Pascasarjana, UNIBA.

Putong, (2010). Pengantar Ekonomi Mikro Dan Makro. Jakarta: Mitra Wacana Media. 
Sakti, A (2013). Manajemen Transportasi

Sanusi, A (2011). Metodelogi Penelitian Bisnis. Jakarta: Salemba Empat

Sugiyono, (2013). Metode penelitian kuantitatif kualitatif dan R\&D. Bandung: CV. Alfabeta.

Sugiyono, (2017). Metode penelitian dan pengembangan. Bandung: CV. Alfabeta

Sunyoto, D, (2015). Prilaku konsumen dan pemasaran. Edisi pertama. Jakarta: Center For Academic Publishingservice.

Amelia, W.R. (2017). Pengaruh Experiental Marketing Terhadap Minat Beli ulang Pelanggan Pada Rumah Makan Beringin Indah Pematang Siantar. JKBM (JURNAL KONSEP BISNIS DAN MANAJEMEN), 4 (1): 50-60.

Lubis, A. (2014). Pengaruh Kualitas Pelayanan Pendidikan Terhadap Kepuasan Dan Loyalitas Pada Mahasiswa Fakultas Ekonomi Universitas Medan Area Medan. JKBM (Jurnal Konsep Bisnis Dan Manajemen), 1(1): 29-36.

Sihaloho,S,H. Mulia,U,A.(2016). Pengaruh Strategi Promosi Terhadap Keputusan Pembelian Konsumen Pada Carrefour Citra Garden Medan. Jurnal Akuntansi dan Bisnis, 2 (2): 81-96

Mulia,U, Isnaniah.(2016) Analisis Kualitas Pelayanan Terhadap Kepuasaan Pelanggan Pada PT.Central Santosa Finance (CSF) Cabang Pematang Siantar. Jurnal Poliprofesi. 11(1): 32-49 